LA W RENCE LIVERMORE NATIONAL LABORATORY
2013 LIDAR Campaign at Buena Vista Wind Farm: An Examination of Hill \#Speedup\# Flows

S. Wharton, G. Qualley, J. Newman, W. Miller 
This document was prepared as an account of work sponsored by an agency of the United States government. Neither the United States government nor Lawrence Livermore National Security, LLC, nor any of their employees makes any warranty, expressed or implied, or assumes any legal liability or responsibility for the accuracy, completeness, or usefulness of any information, apparatus, product, or process disclosed, or represents that its use would not infringe privately owned rights. Reference herein to any specific commercial product, process, or service by trade name, trademark, manufacturer, or otherwise does not necessarily constitute or imply its endorsement, recommendation, or favoring by the United States government or Lawrence Livermore National Security, LLC. The views and opinions of authors expressed herein do not necessarily state or reflect those of the United States government or Lawrence Livermore National Security, LLC, and shall not be used for advertising or product endorsement purposes.

This work performed under the auspices of the U.S. Department of Energy by Lawrence Livermore National Laboratory under Contract DE-AC52-07NA27344. 


\title{
2013 LIDAR Campaign at Buena Vista Wind Farm: An Examination of Hill "Speedup" Flows
}

\author{
Sonia Wharton ${ }^{1}$, Grant Qualley ${ }^{2}$, Jennifer Newman ${ }^{3}$, and Wayne Miller ${ }^{1}$
}

${ }^{1}$ Lawrence Livermore National Laboratory, Livermore, California

${ }^{2}$ Infigen Energy, Dallas, Texas

${ }^{3}$ University of Oklahoma, Norman, Oklahoma

September 25, 2013

\section{Introduction}

In June 2013, two Laser and Detection Ranging (lidar) units (ZephIR 300, Natural Power, North Ledbury, England) were deployed at the Buena Vista Wind Farm in the Altamont Hills region of California until mid-August of that year. This was the third field campaign at Buena Vista for the 12-ERD-069 project, following a winter campaign in 2011-2012 and a summer campaign in 2012. The lidar data provided wind measurements at the base ("flatland" lidar) and along the slope ("hill" lidar) of a ridge to study the flow as it moved up and along the ridge towards turbine A08 under varying stability conditions. The lidars measured wind speed, direction and turbulence at ten measurement heights including ones equivalent to the turbine rotor-disk. Instrument placement is shown in Figures 1 and 2 . The placement of the two lidars was based on wind direction measurements taken at the hill lidar location during summer of 2012. The predominant wind direction in 2013 was nearly identical to 2012 and the lidar locations proved optimal for capturing wind flow as it approached A08 from the southwest. SCADA data provided 10-minute nacelle wind speed and power data for the nearby turbines.

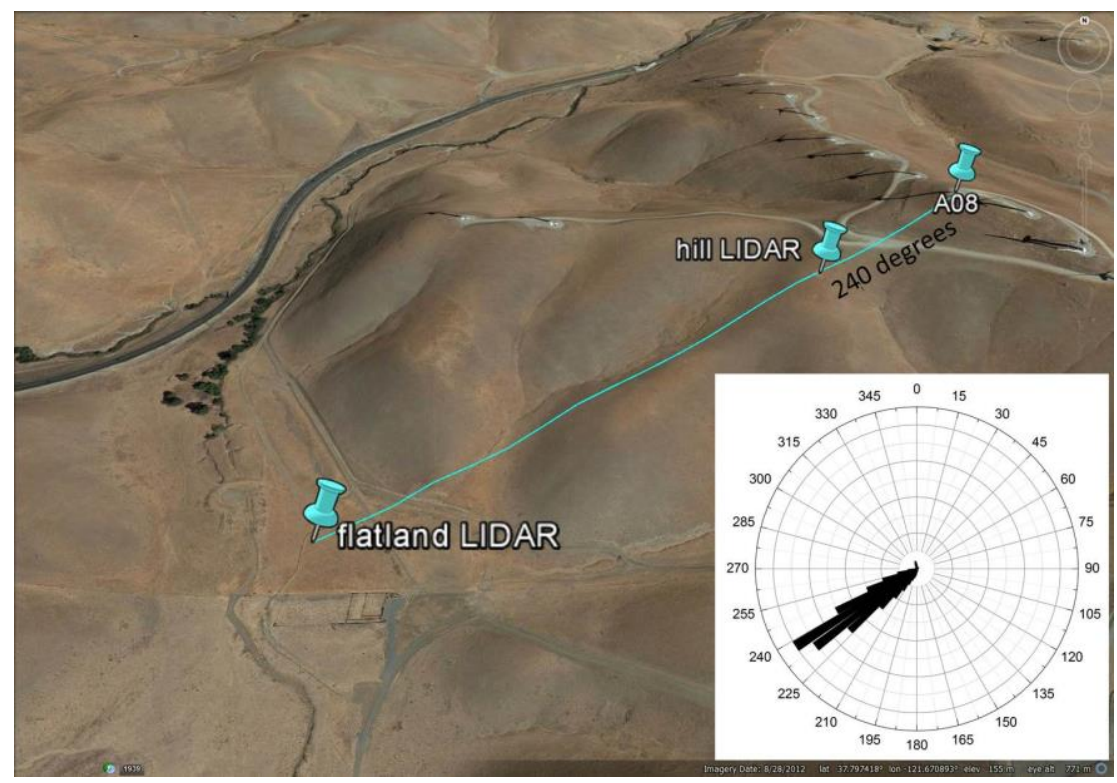

Figure 1: Satellite image of the Buena Vista Wind Farm showing the locations of the flatland lidar (\#345, 37.7958, -121.6736; $120 \mathrm{~m}$ a.s.I.), hill lidar (\#355, 37.7987, -121.6676; $220 \mathrm{~m}$ a.s.l.), and downwind turbine A08 (37.7997, -121.6655, $260 \mathrm{~m}$ a.s.l.) as well as the wind direction at the flatland lidar (measurement height $=193 \mathrm{~m}$ a.g.l.) during the campaign period. Buena Vista is located in the Altamont Pass Wind Resource Area in Contra Costa County, California. 

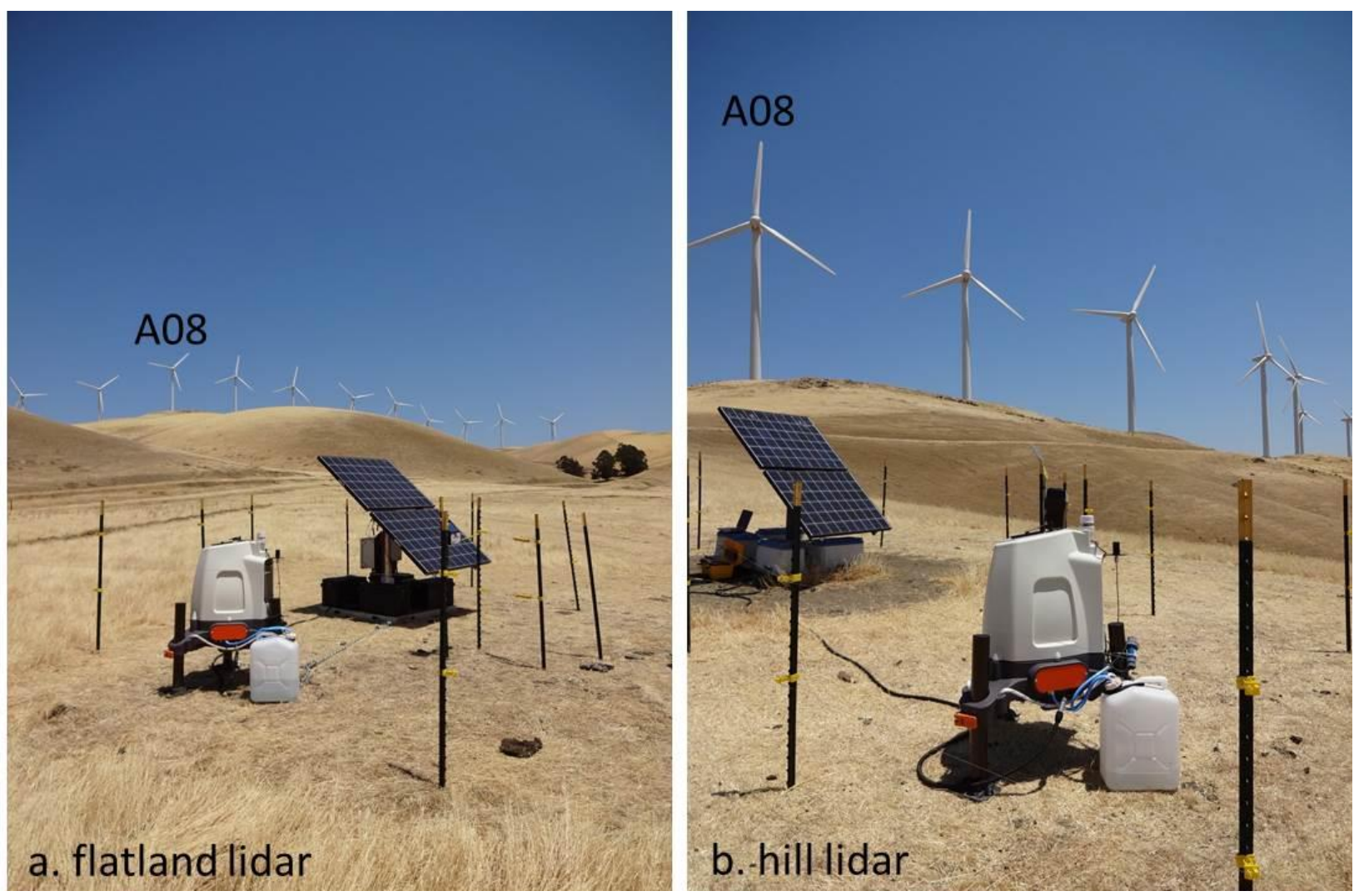

Figure 2: Photographs showing the (a) flatland lidar and (b) hill lidar. The flatland lidar (\#345) was $850 \mathrm{~m}$ downwind of turbine A08 or nearly 14 rotor diameters $(D)$ away. The hill lidar (\#355) was $220 \mathrm{~m}$ downwind of A08 or $3.5 D$ away. Both lidars were placed along a line of sight at an angle of 240 degrees from A08.

The landscape surrounding Buena Vista includes the Cañada de los Vaqueros hills to the west and south, and is moderately complex topography as shown in Figure 3. The surrounding hills have maximum heights of around $400 \mathrm{~m}$ a.s.l. although most hills are $200 \mathrm{~m}$ a.s.I. or less. The surface roughness is small and uniform as the land is devoid of trees and is used for grazing. Local flow during the summer is influenced by three topographical features of increasing scale: the surrounding hills and ridgelines, the canyon along Vasco Road, and the sea breeze. On the regional-scale the flow is controlled by strong diurnal temperature contrasts between the land and Pacific Ocean which drives strong sea breezes from the southwest. Landscape-scale winds are influenced by a narrow canyon along Vasco Road which further funnels the southwesterly flow. Hills and ridgelines perturb the localized flow features.

As air travels over a complex landscape, changes occur to the mean and turbulent components of that flow. One of these changes is the acceleration of flow over hill crests due to a pressure minimum that develops at the top of the hill and is accompanied by streamline convergence on the windward side (e.g., Taylor et al. 1987, Kaimal and Finnigan 1994). To measure this expected acceleration the "flatland" lidar was placed at the bottom of an elongated ridge and the "hill" turbine was placed approximately $3 / 4$ of the way up the ridgeline. A lidar was not placed at the crest of the ridge among the turbines in row $A$ because the distance between turbines was too short for a clean measurement. For example, at a 
measurement height of $150 \mathrm{~m}$ a.g.l. the sample volume is $160 \mathrm{~m}$ across. The turbines in row $\mathrm{A}$ are $\sim 90-$ $100 \mathrm{~m}$ apart but only $\sim 30-40 \mathrm{~m}$ of that distance is blade-free.

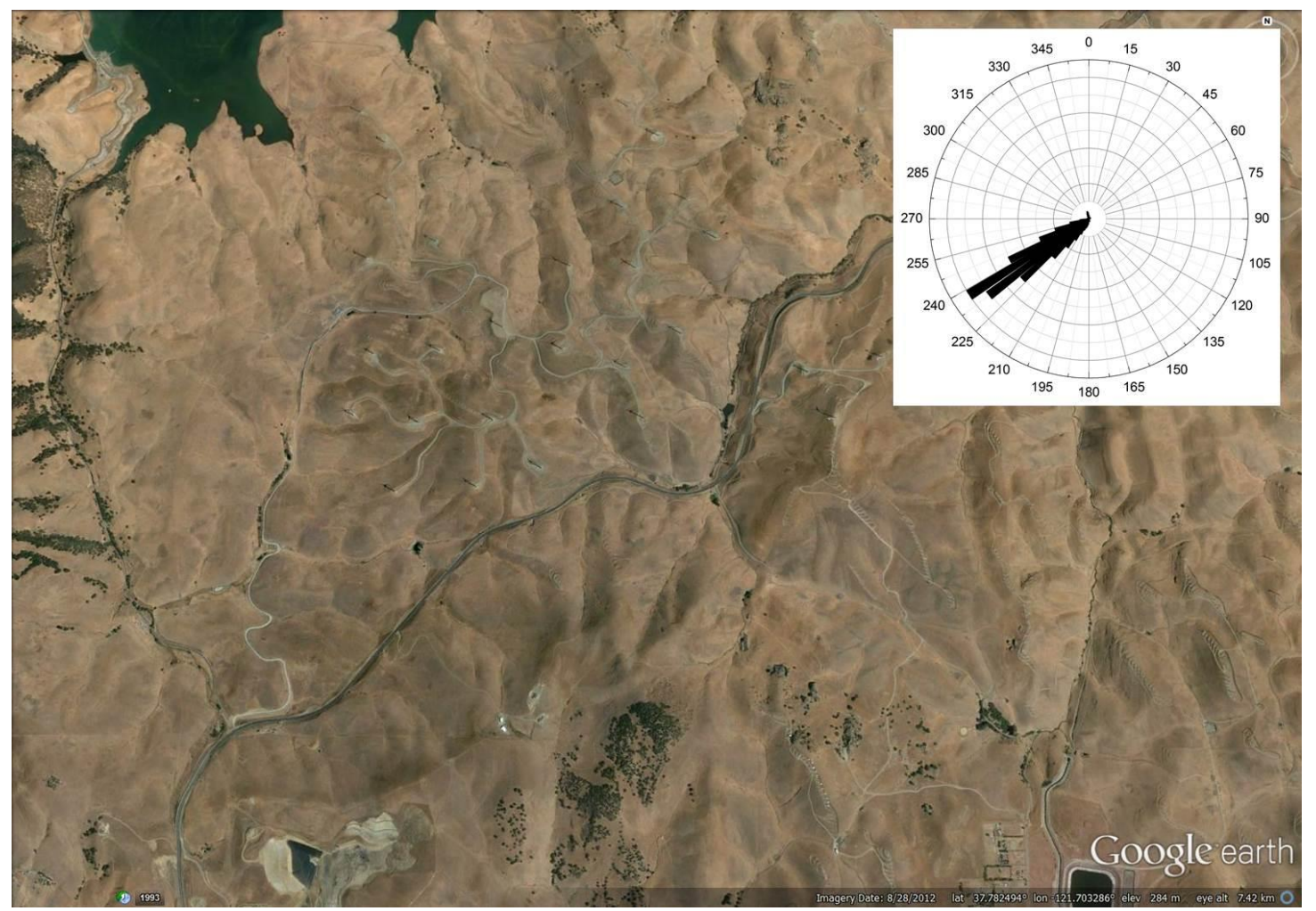

Figure 3: Satellite image of the surrounding landscape with the location of the Buena Vista wind farm represented by the center of the wind rose. The terrain is complex and includes a small canyon along Vasco Road, orientated southwest-northeast, which likely funnels the direction of the flow, and numerous hills and ridgelines which run mostly northwest to southeast. Most of the nearby hills range in height from $100 \mathrm{~m}$ a.s.l. to $400 \mathrm{~m}$ a.s.l.

The Buena Vista wind farm consists of 38 turbines and has a total generating capacity of $38 \mathrm{MW}$. The wind turbines are blade-pitch controlled, $1 \mathrm{MW}$ Mitsubishi, MWT62-1000A. Cut-in speed is $3.0 \mathrm{~m} / \mathrm{s}$, rated speed is $12.5 \mathrm{~m} / \mathrm{s}$, and cut-out speed is $25 \mathrm{~m} / \mathrm{s}$. Cup anemometers are mounted on the nacelle downwind of the turbine blades and measure the wind speed at hub-height at a frequency of $1 \mathrm{~Hz}$. Hubheight is $55 \mathrm{~m}$, rotor diameter is $61.4 \mathrm{~m}$ and blade length is $29.5 \mathrm{~m}$ for the Row A turbines. This puts the minimum blade distance above ground at $24 \mathrm{~m}$ and maximum blade distance above ground at $86 \mathrm{~m}$.

The lidars were configured to optimize measurements so that overlapping heights above ground level were measured by both lidars as well as heights equivalent to the rotor-disk of turbine A08. A schematic of the lidar configurations is shown in Figure 4. Exact measurement heights for each lidar are listed in Table 1. Each lidar was powered by $12 \mathrm{~V}$ DC provided by two solar panels and six $12 \mathrm{~V}$ DC batteries. Electric cow fences were installed around the units and solar panels to prevent animal damage. Lidar \#345 is owned by LLNL and was purchased through a SMS grant in FY13. Lidar unit \#355 was rented from Natural Power through Campbell Scientific for the duration of the field campaign. 


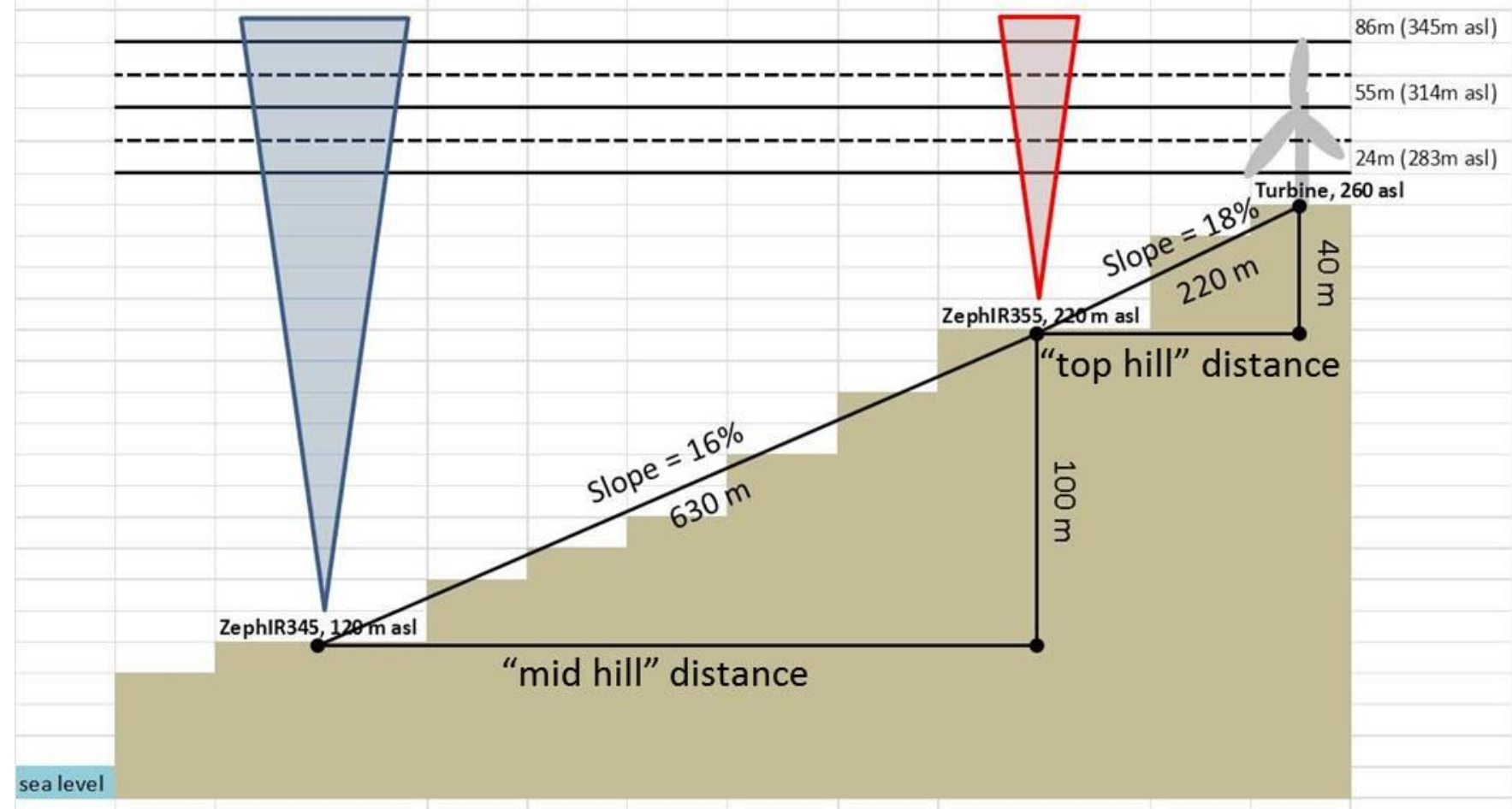

Figure 4: Schematic of the lidar deployment in 2013 at the Buena Vista Wind Farm. Each lidar was configured to measure wind speed and direction at high-resolution above the ground surface as well as at heights equivalent to turbine A08's rotor disk. Slope between the flatland and hill lidars was $16 \%$; slope between the hill lidar and turbine A08 was $18 \%$. The predominant wind is 240 degrees which is from the left hand side of the figure.

Table 1: Measurement heights for the lidars and turbine A08 nacelle cup anemometer given as meters above ground level (a.g.l.) and meters above sea level (a.s.l.). Overlapping a.g.l. heights are in gray, overlapping a.s.l. heights are in green.

\begin{tabular}{|l|l|l|l|l|l|l|}
\hline $\begin{array}{l}\text { Measurement } \\
\text { level }\end{array}$ & $\begin{array}{l}\text { Flatland lidar } \\
(\mathbf{m}) \text { (a.g.I.) }\end{array}$ & $\begin{array}{l}\text { Hill lidar }(\mathbf{m}) \\
\text { (a.g.I.) }\end{array}$ & $\begin{array}{l}\text { Turbine A08 } \\
(\mathbf{m}) \text { (a.g.I.) }\end{array}$ & $\begin{array}{l}\text { Flatland lidar } \\
(\mathbf{m}) \text { (a.s.I.) }\end{array}$ & $\begin{array}{l}\text { Hill lidar }(\mathbf{m}) \\
\text { (a.s.I.) }\end{array}$ & $\begin{array}{l}\text { Turbine A08 } \\
\text { (m) (a.s.I.) }\end{array}$ \\
\hline ground & 0 & 0 & 0 & 120 & 220 & 260 \\
\hline 1 & 10 & 10 & 55 & 130 & 230 & 315 \\
\hline 2 & 24 & 24 & & 144 & 244 & \\
\hline 3 & 38 & 38 & & 158 & 258 & \\
\hline 4 & 55 & 55 & & 175 & 275 & \\
\hline 5 & 75 & 63 & & 195 & 283 & \\
\hline 6 & 86 & 75 & & 206 & 295 & \\
\hline 7 & 112 & 86 & & 232 & 306 & \\
\hline 8 & 124 & 94 & & 244 & 314 & \\
\hline 9 & 163 & 112 & & 283 & 332 & \\
\hline 10 & 194 & 120 & & 314 & 340 & \\
\hline 11 & 225 & 125 & & 345 & 345 & \\
\hline
\end{tabular}




\section{LIDAR observations}

Lidar data were archived at two frequencies: $\sim 1 \mathrm{~Hz}$ and 10-minute averages. The 10 minute data were emailed nightly by the lidar units via a wireless modem to LLNL. The high resolution data ( $1 \mathrm{~Hz})$ was downloaded remotely from unit \#345 using Natural Power's Waltz software. We were unable to download the high frequency data from unit \#355 due to a software glitch with this unit. The $1 \mathrm{~Hz}$ data was mailed to LLNL by Campbell Scientific at the end of the campaign when this unit was returned to the vendor.

\section{2a. Livermore lidar inter-comparison study}

Prior to the deployment at Buena Vista, the two lidar systems were placed side by side at LLNL's main campus in a field just north of Building 170 (37.6905, -121.7163) to assess measurement agreement. The inter-comparison period lasted from May 31-June 4, 2013. The units were placed $\sim 10 \mathrm{~m}$ apart on very flat land with no trees, buildings or other obstructions within the immediate area (within $200 \mathrm{~m}$ ). Both lidars were set up in an identical manner using solar and battery power units. Measurement heights included: $10,20,30,38,40,50,60,70,80,90$ and $100 \mathrm{~m}$ a.g.l.

Wind speed comparisons between unit \#345 and \#355 showed excellent agreement for all heights. Linear correlation (Pearson's r) values ranged from 0.990 at $10 \mathrm{~m}$ to 0.997 at $100 \mathrm{~m}$. Linear regression plots for these heights are shown in Figure 5. Agreement in wind direction between the units was also excellent. Pearson's $r$ values ranged from 0.981 for $10 \mathrm{~m}$ to 0.99 for $100 \mathrm{~m}$ (Figure 6). Accuracy increased with height for both wind speed and wind direction.
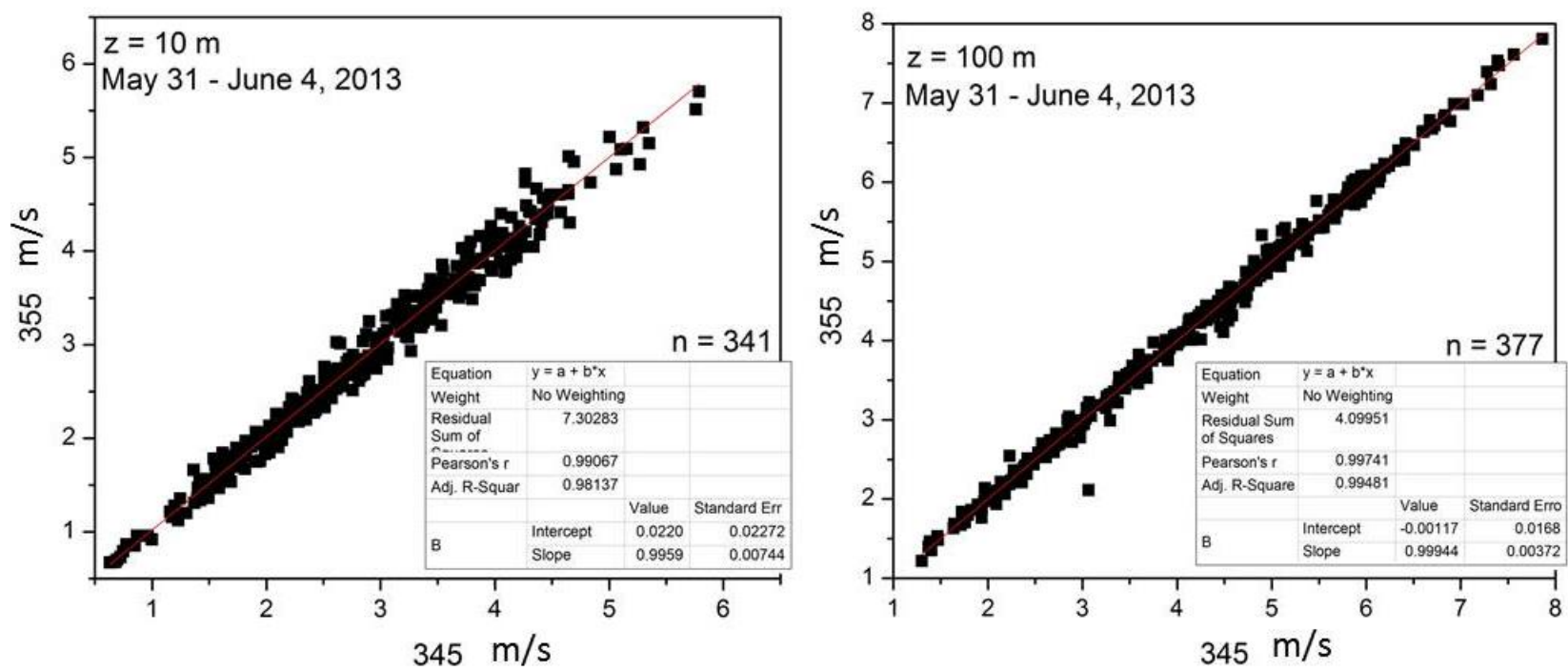

Figure 5: Excellent wind speed agreement was found between the two lidar units during a short intercomparison study done in Livermore, CA prior to the Buena Vista deployment. Wind speeds measurements taken at $10 \mathrm{~m}$ and $100 \mathrm{~m}$ a.g.l. are shown. 

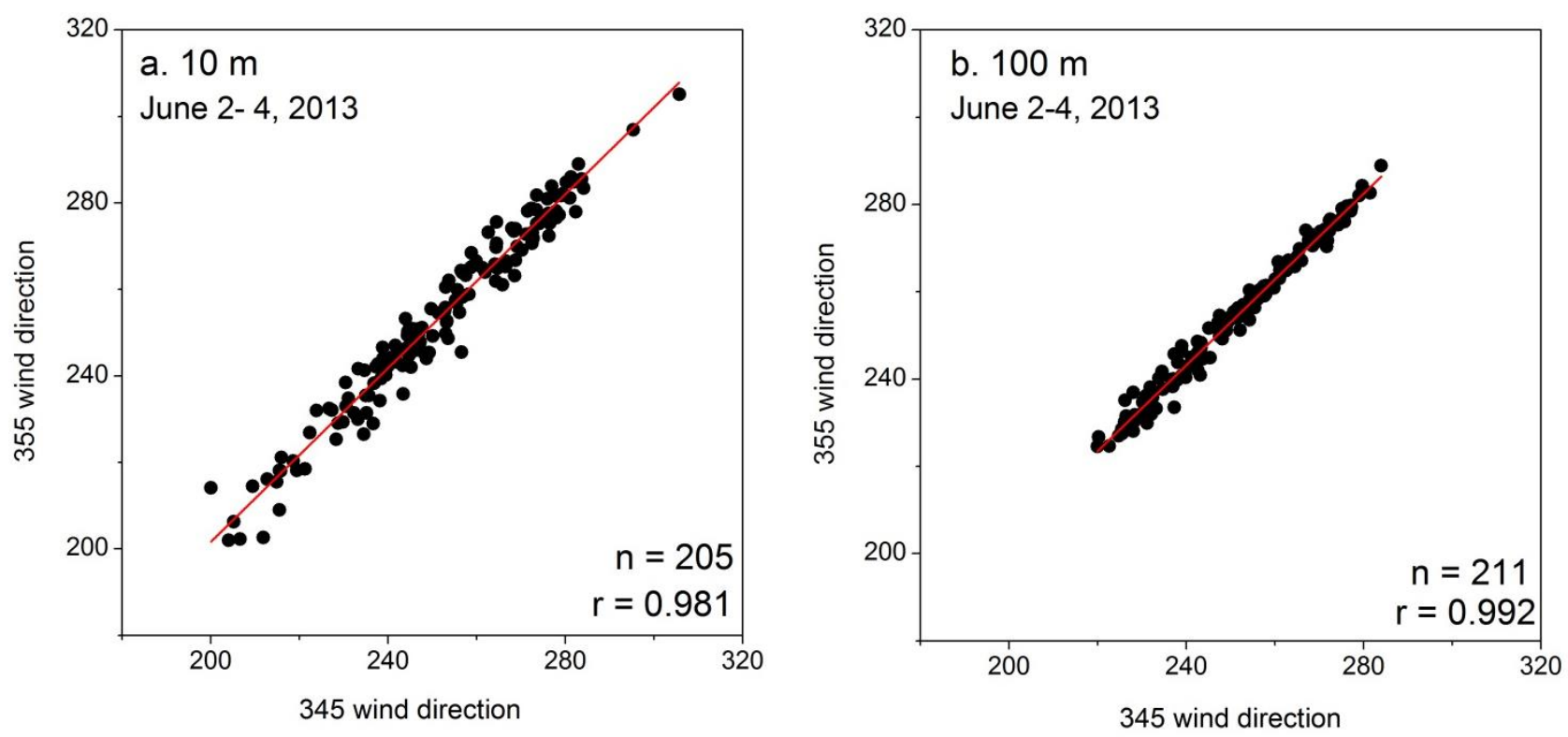

Figure 6: High wind direction agreement was also found between the two lidars during a short intercomparison study. The plots here contain fewer data points than Figure 5 because the units were readjusted for compass alignment on June 2 . The near-surface $(10 \mathrm{~m})$ wind direction had a greater southwesterly component than winds higher aloft (100 m).

\section{2b. Buena Vista wind direction}

The Buena Vista 10-minute measurements were filtered to ensure that observations were available for both lidars for any given 10-minute period. The dominant wind direction at both lidars was from the southwest. At the flatland lidar the percentage of winds from $230-250$ degrees ranged from $42 \%$ at $10 \mathrm{~m}$ a.g.l. to $53 \%$ at $162 \mathrm{~m}$. At the hill lidar, the percentage of winds from $230-250$ degrees ranged from $44 \%$ at $10 \mathrm{~m}$ a.g.l. to $57 \%$ at $124 \mathrm{~m}$ a.g.l. The wind roses indicate that the alignment of each lidar was slightly different even though steps were made to ensure that they both faced true north (this was manually done with several hand held compasses and GPS units). This disagreement is seen in the slight shift between the dominant wind direction at the flatland lidar (238-242 degrees) and the hill lidar (240-244 degrees) and is also apparent in the same magnitude in the northerly flow component. This multidirectional offset indicates a compass heading error versus a terrain-induced flow feature which would be directionally-dependent. The misalignment, however, was less than five degrees.

Wind direction was most uniform during the midday hours when the atmosphere was well-mixed. For these hours (10:00 - 14:00 PST), wind direction changed little with height and changed little between lidar units (Figure 7). The nighttime (22:00-4:00 PST) wind direction plots had greater variability which was both height- and location-dependent. The nighttime wind roses also indicate the presence of a couple of flow obstructions (e.g., hills) which influenced the near surface flow (Figures 8-10). 


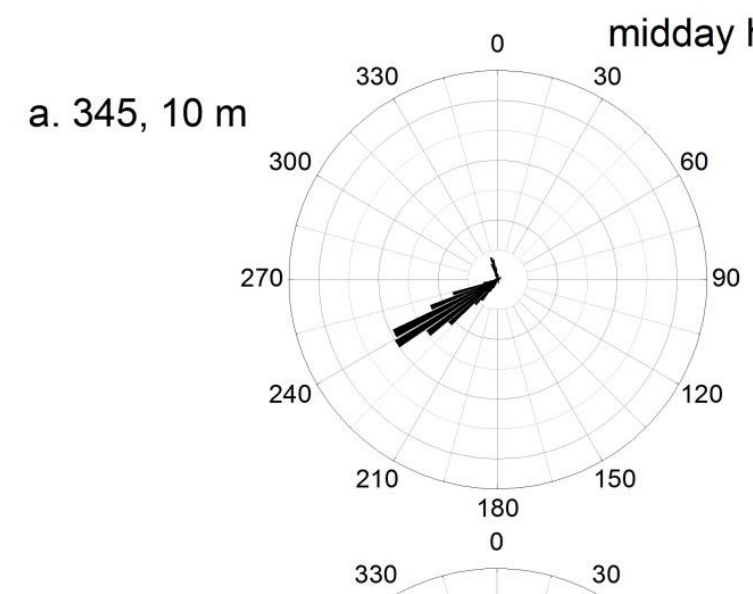

c. $345,55 \mathrm{~m}$

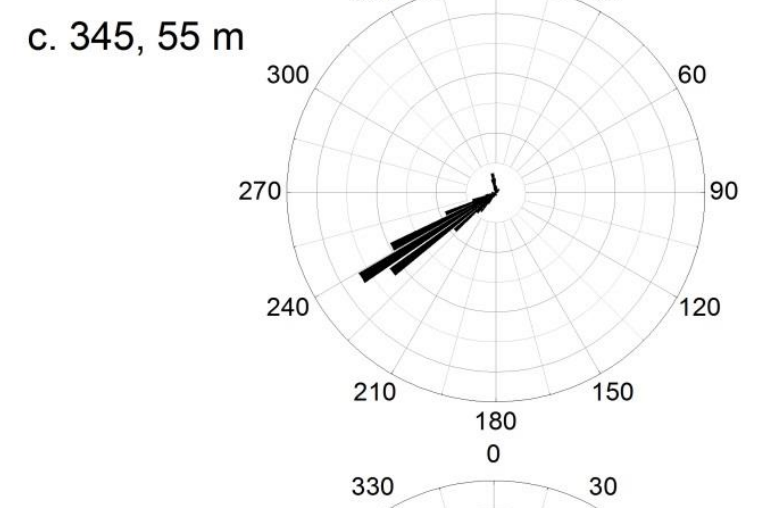

e. $345,86 \mathrm{~m}$
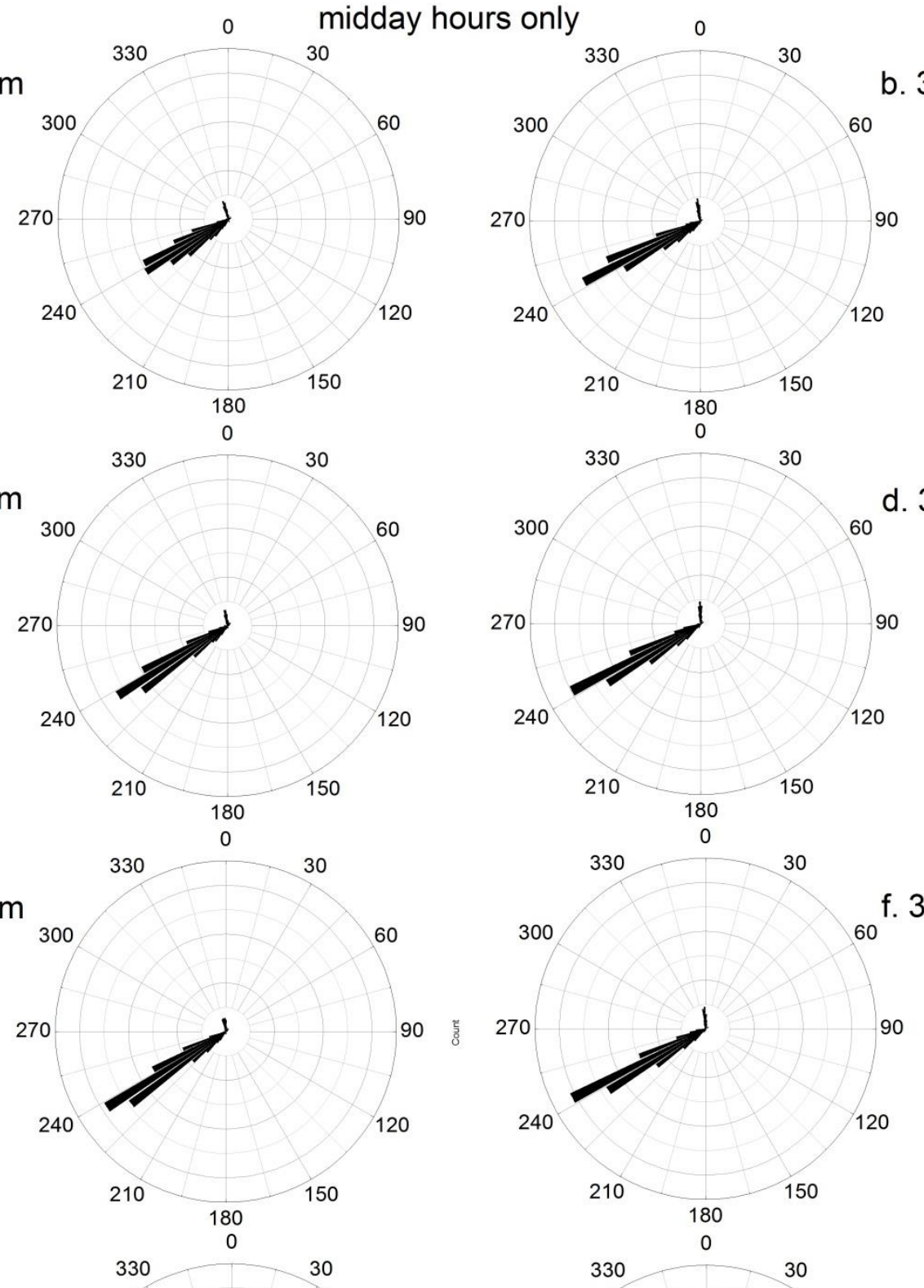

b. $355,10 \mathrm{~m}$
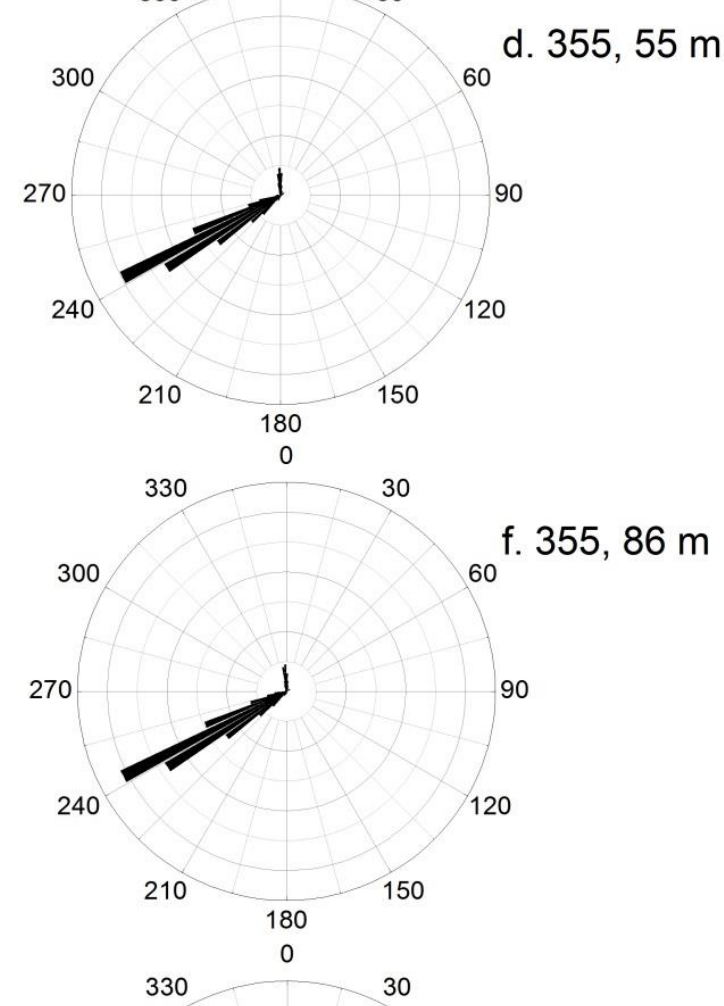

g. $345,125 \mathrm{~m}$
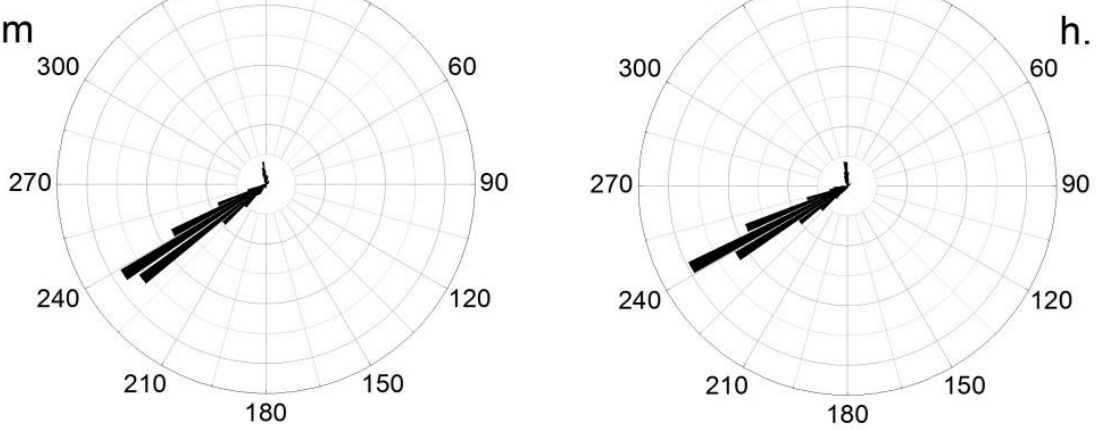

Figure 7: Midday wind direction frequency plots for the flatland (\#345) and hill (\#355) lidar based on four measurement heights: 10, 55, 86 and $125 \mathrm{~m}$ a.g.l. Wind direction is essentially identical at both lidars (there is a slight instrument misalignment which explains the small offset as mentioned in the text) and the predominant wind direction is from the southwest at both locations. 

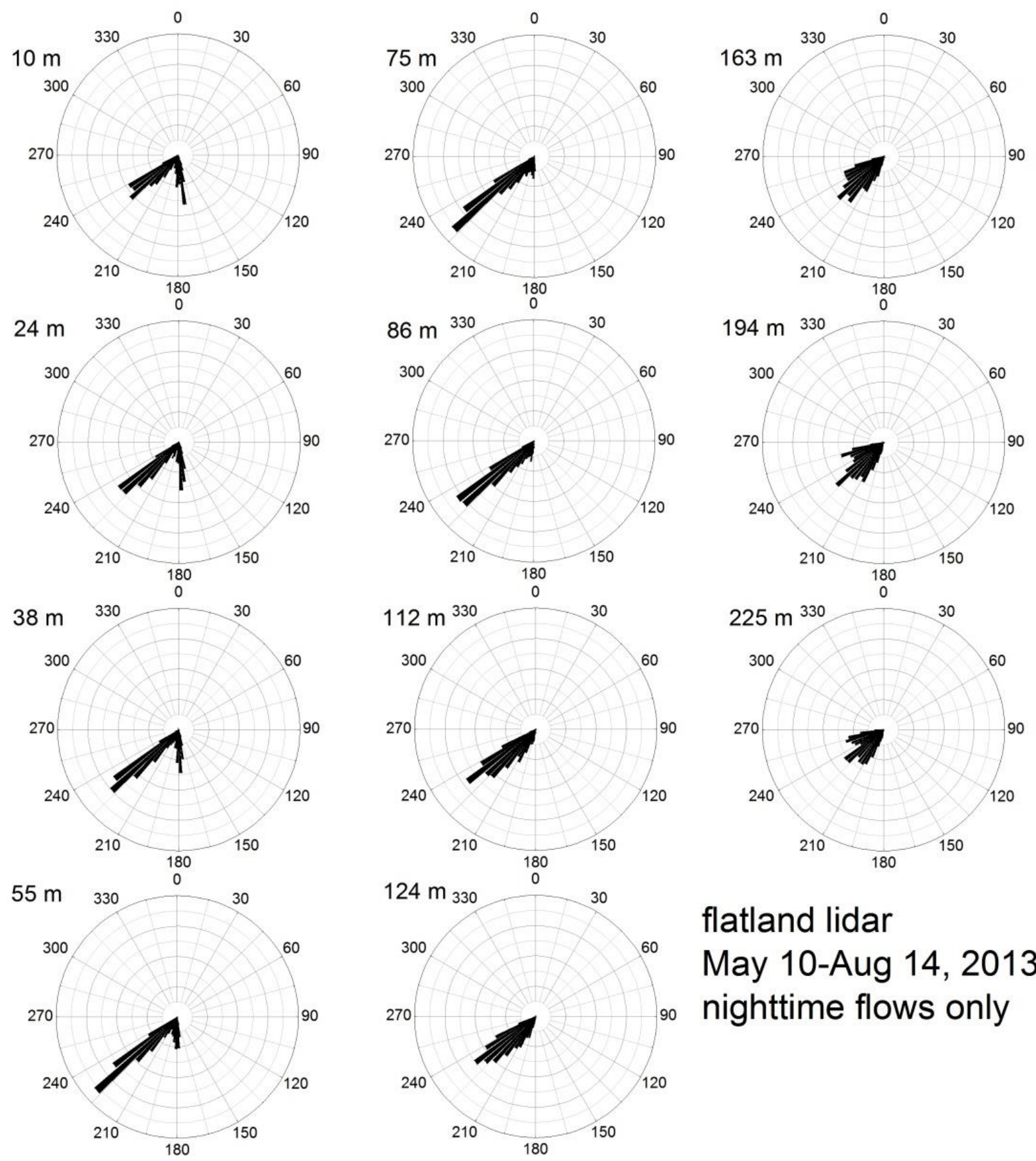

\section{flatland lidar \\ May 10-Aug 14, 2013 nighttime flows only}

Figure 8: Nighttime wind direction frequency plots for the flatland lidar based on measurement height (a.g.l.). Flow obstruction is observed for the near-surface heights ( $55 \mathrm{~m}$ and below) between 190-205 degrees. Strongly channeled, terrain-induced flow is also observed for the lower heights which becomes less apparent above $122 \mathrm{~m}$ a.g.l. 
Close to the ground at the flatland lidar, the winds came from either the southwest or south-southeast as it appears that some of the southwesterly surface flow is obstructed and re-directed to the southsoutheast by a hill that is orientated 190-205 degrees from the lidar (Figure 9). Above $122 \mathrm{~m}$ it appears that the local terrain plays less of a role in determining wind direction. Although the winds remain to come from the southwest the flow is less channeled than at lower heights and is more indicative of regionally-forced flow.

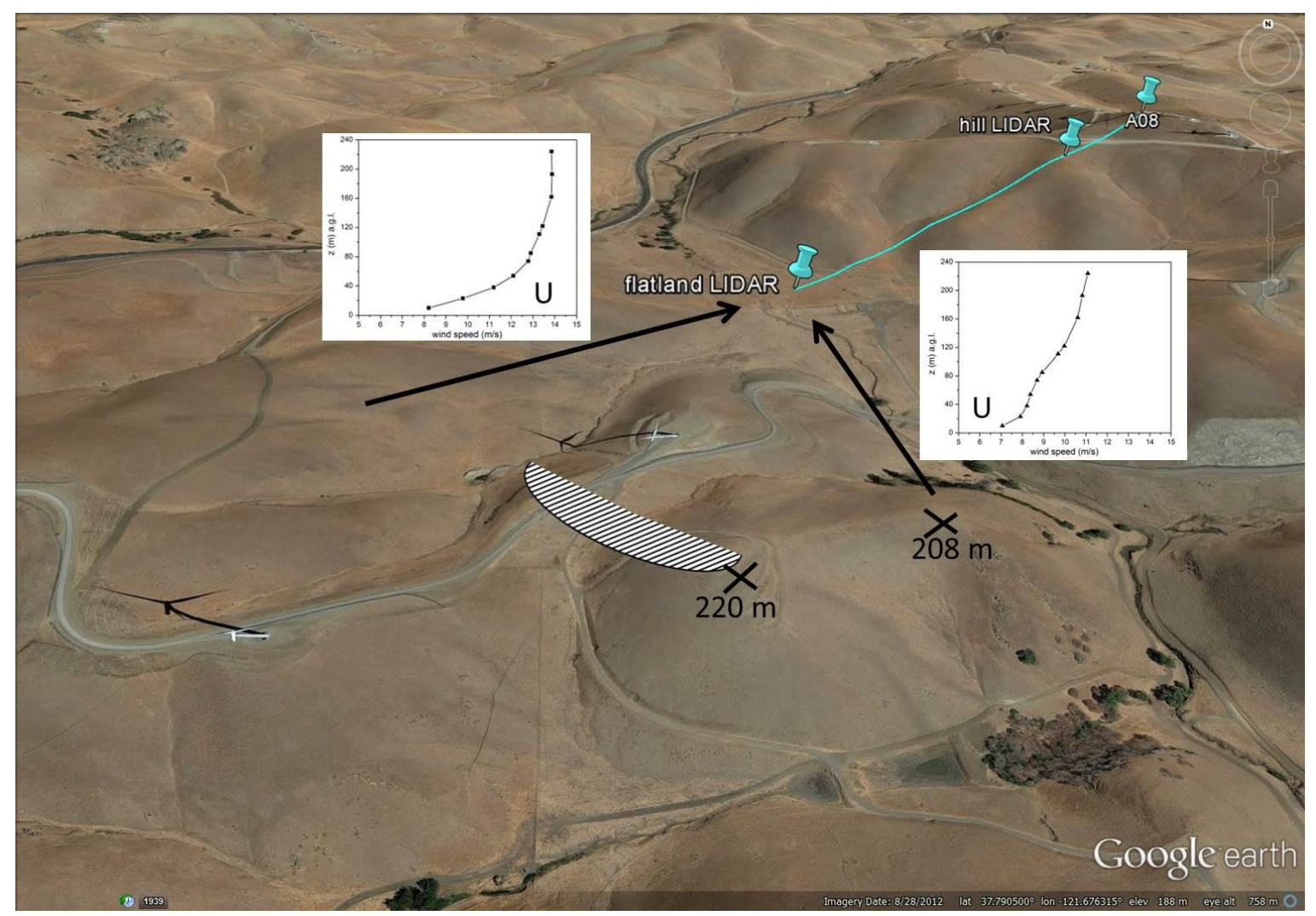

Figure 9: Satellite map showing the immediate terrain upwind of the flatland lidar and nighttime wind vectors and profiles at this location. The predominant wind direction is from the southwest but some of that flow is redirected by a $220 \mathrm{~m}$ tall hill and a south-southeasterly wind component is also apparent at the lidar at heights below $55 \mathrm{~m}$. The drawn arc represents the boundaries of the flow obstacle which has its strongest influence on the western side of the hill. Also shown are the nighttime mean wind speed profiles according to these wind directions.

At the hill lidar, the nighttime flows do not exhibit a south-southeasterly component, indicating that the near-surface flow obstacle at the flatland lidar has only a localized effect. Instead, at the hill lidar, channeled flow from the southwest increases with height as the wind rose is most variable close to the surface. There appears to be a small obstacle at 210-220 degrees which slightly re-directs the flow close to the surface but its influence disappears above $40 \mathrm{~m}$ (Figure 10).

Directional wind shear, or vear, is plotted in Figure 11 for heights representing the bottom half of the rotor disk as well as the top half. Greater vear is observed in the bottom half of the rotor at both lidar locations. During the day, greater vear is observed at the flatland lidar but at night, the hill lidar saw 
significantly higher directional shear. Directional shear is skewed towards positive numbers indicating a clockwise rotation of the wind with height.
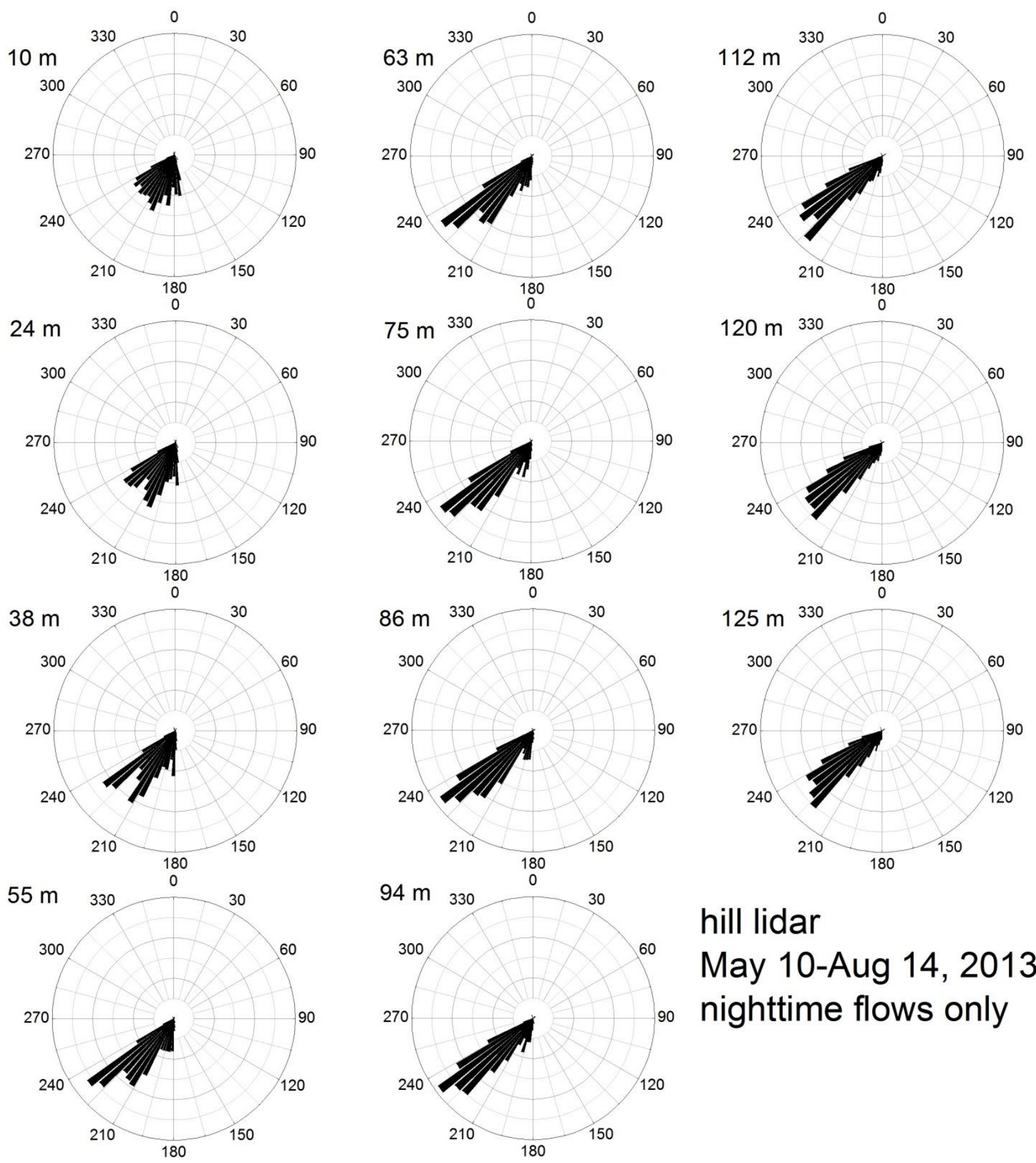

Figure 10: Nighttime wind direction frequency plots for the hill lidar based on measurement height (a.g.l.). Here, the flow becomes more channeled once a height of $55 \mathrm{~m}$ is reached. Nighttime flows at the hill lidar are almost always from 210-240 degrees, with a slight southerly component visible at heights closest to the surface. 


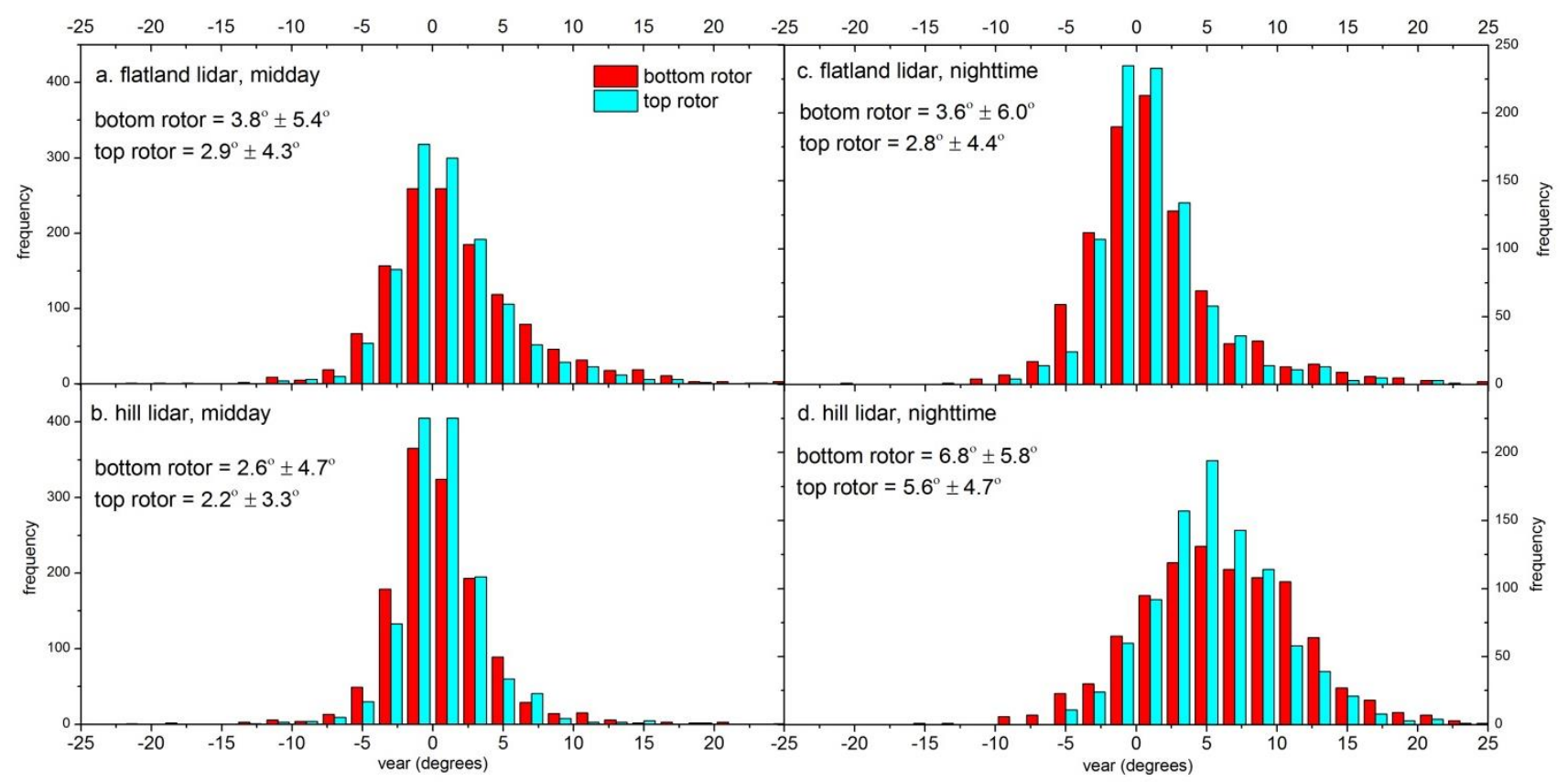

Figure 11: Histograms of midday and nighttime wind direction shear (vear) for the flatland and hill lidars. The data are separated into the top portion of the rotor disk ( $85 \mathrm{~m}$ to $55 \mathrm{~m}$ ) and the bottom portion of the rotor disk (55 $\mathrm{m}$ to $23 \mathrm{~m}$ ). Strongest vear is observed at the hill lidar during nighttime hours for heights equivalent to the bottom half of a turbine rotor disk and averages 6.8 degrees.

\section{2c. Buena Vista wind speed profiles}

The wind speed data presented in this section were screened for wind direction and data availability. We used a 20 degree wind sector to ensure that we captured the wind flow as it traveled along the hill past the lidars and towards the turbine. Only winds from $230^{\circ}-250^{\circ}$ were included and wind direction screening was based on the "hub-height" equivalent measurement level for each lidar, i.e., the level equivalent to 315 a.s.l. Data were also screened to ensure that measurements were available for both lidars and the turbine for any given 10-minute period. Profiles by time of day are shown in Figures 12 and 13 for both lidars as well as the nacelle hub-height wind speed at turbine A08. Figure 12 shows the measurement heights in meters above sea level while the heights are plotted as a function of meters above ground level in Figure 13. 


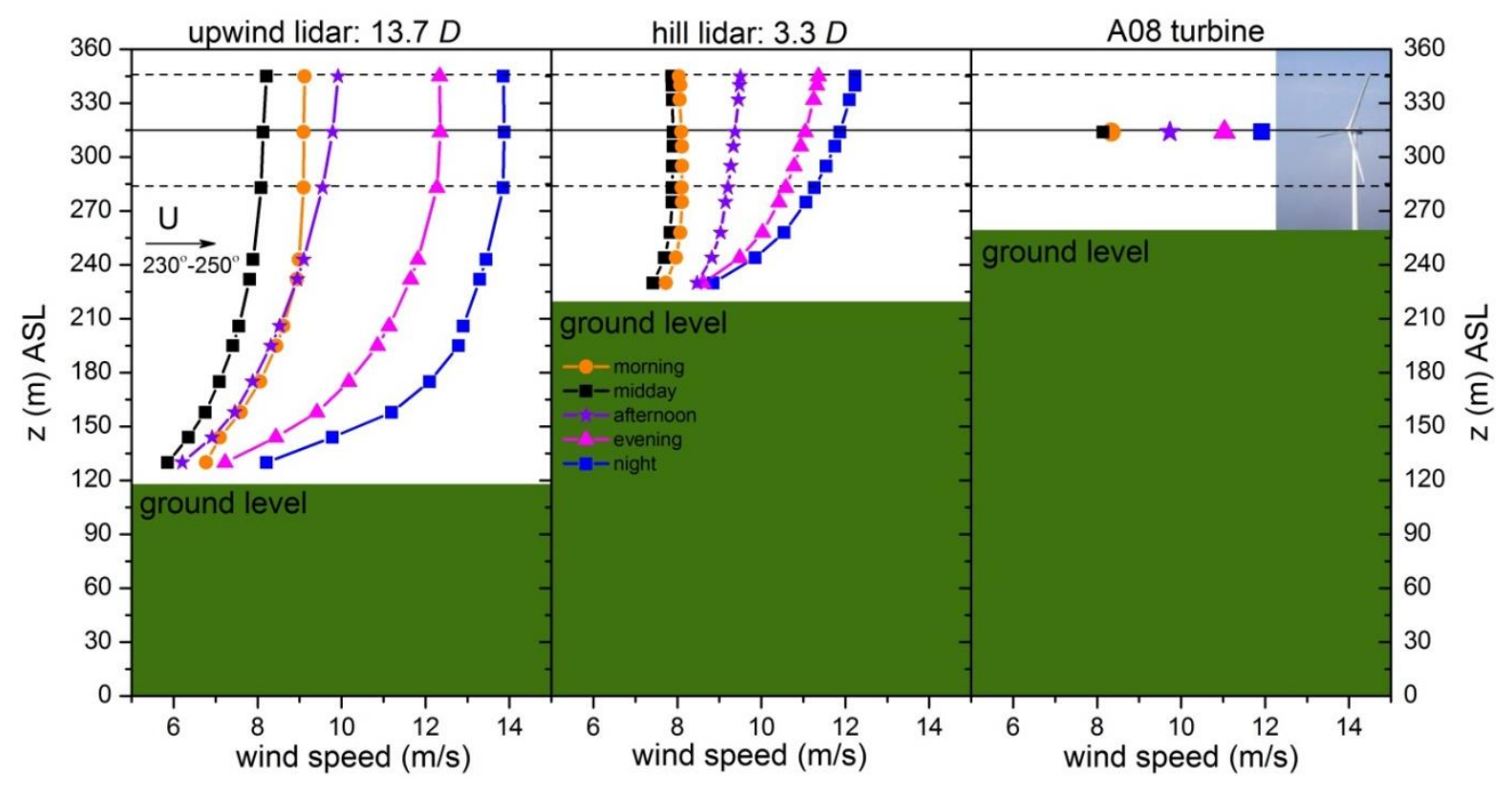

Figure 12: Mean wind speed profiles for the flatland or upwind lidar and hill lidar by time of day compared to the nacelle wind speed at A08. The measurement heights are a function of meters above sea level. Within the first $100 \mathrm{~m}$ above ground level, wind shear is higher for the flatland lidar than the hill lidar as the wind vectors are compressed as they move along the top of the hill.

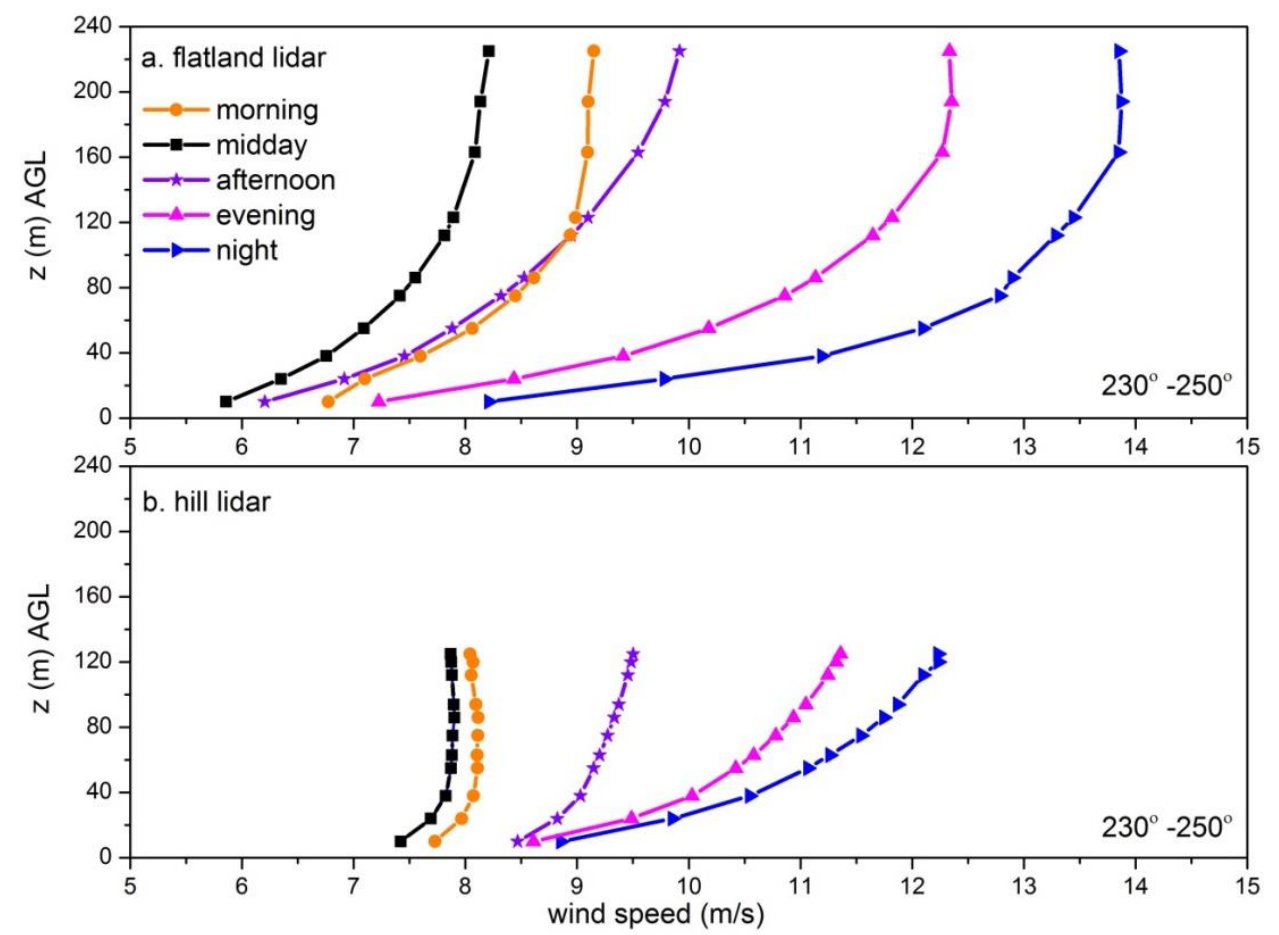

Figure 13: Mean wind speed profiles for the (a) flatland lidar and (b) hill lidar plotted as a function of height above ground level. Wind shear is compressed for the hill lidar during all hours of the day in comparison to the flatland lidar. 
For a closer comparison, the mean wind speed profiles and mean nacelle wind speed are also plotted in Figures $14-18$ by time of day. These plots show the profiles in height above ground level and height above sea level as the elevation differences between the instruments and turbine sometimes complicate the picture. From these data, we calculated:

1. A total hill "speed up" defined as the difference between the nacelle wind speed (55 $\mathrm{m}$ a.g.l.) and the flatland lidar wind speed (55 $\mathrm{m}$ a.g.l.).

2. A top hill "speed up" defined as the difference between the nacelle wind speed (55 $\mathrm{m}$ a.g.I.) and the hill lidar wind speed (55 $\mathrm{m}$ a.g.I.)

3. A mid-hill "speed up" defined as the difference between the hill lidar wind speed (55 m a.g.l.) and the flatland lidar wind speed (55 $\mathrm{m}$ a.g.l.).

These distances are shown in the schematic in Figure 4. A top hill "speed up" effect was strongly evident in the data and the degree of increased speed depended on time of day. The total hill and mid-hill "speed up" effects were much less straightforward as wind speeds at the base of the hill were much higher than expected during the nighttime hours (Figure 18). All "speed-up" magnitudes are listed in Table 2.

Table 2: Hill "speed up" magnitudes depending on time of day and definition. Speed-ups above $0.5 \mathrm{~m} / \mathrm{s}$ are shaded. While strong nighttime flows at the flatland lidar complicate the total hill "speed up" trend, increased "speed up" is seen with increasing atmospheric stability in the top portion of the hill.

\begin{tabular}{|l|l|l|l|l|l|}
\hline "Speed Up" (m/s) & Morning & Midday & Afternoon & Evening & Night \\
\hline Mid-hill & 0.05 & 0.78 & 1.27 & 0.24 & -1.03 \\
\hline Top hill & 0.26 & 0.26 & 0.58 & 0.62 & 0.86 \\
\hline Total hill & 0.31 & 1.04 & 1.85 & 0.86 & -0.17 \\
\hline
\end{tabular}



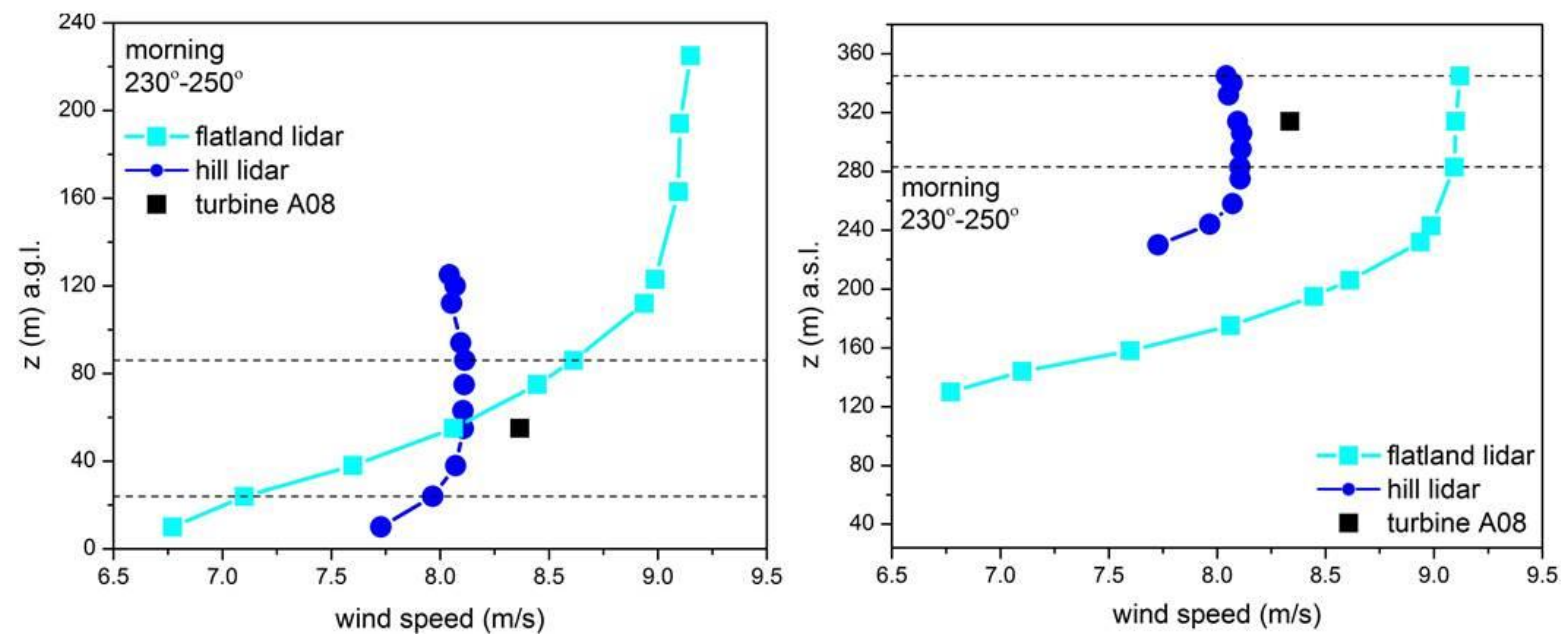

Figure 14: Mean morning wind speed profiles and nacelle wind speed as a function of height. The dashed lines indicate the rotor diameters in meters a.g.l. or meters a.s.l. A top-hill "speed up" effect is clearly visible while a total hill "speed-up" is less clear for the morning hours (left hand panel).
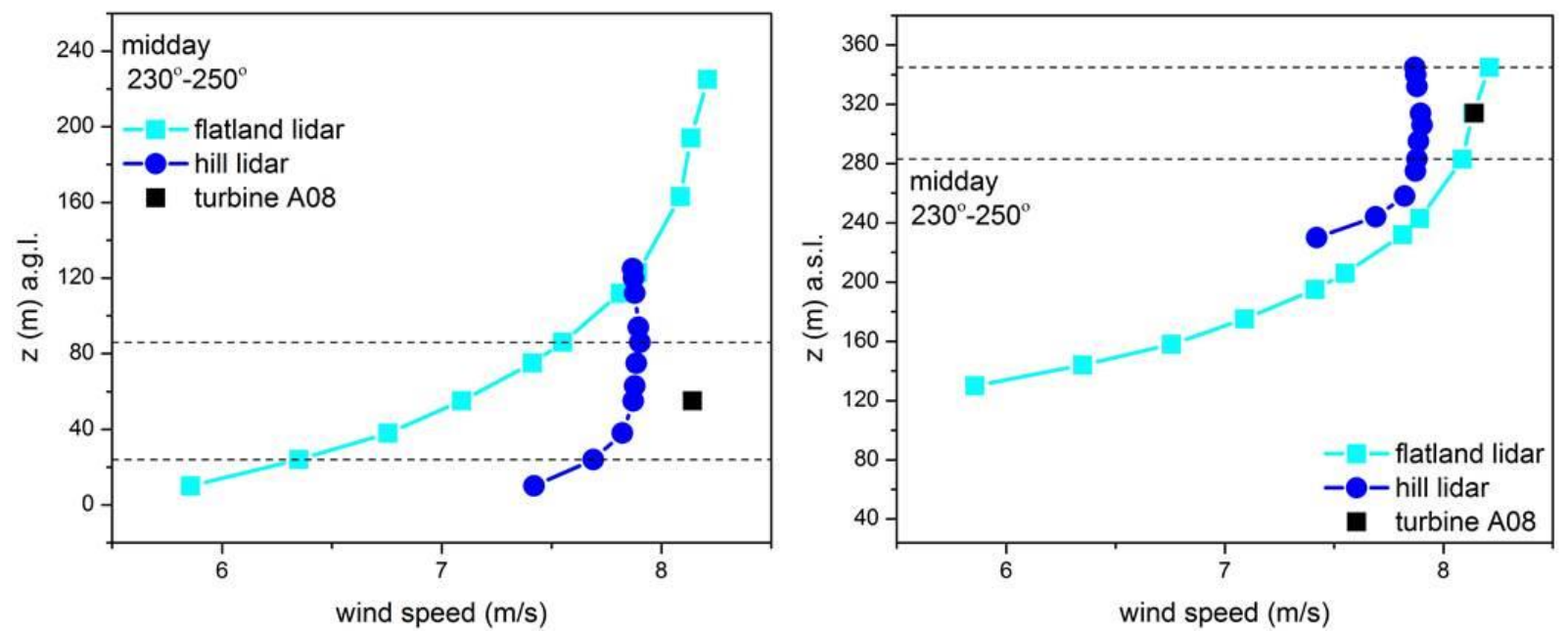

Figure 15: Mean midday wind speed profiles and nacelle wind speed as a function of height. Here, a total hill "speed-up" effect is strongly evident as the wind speed at $55 \mathrm{~m}$ a.g.l. increases as the flow moves up the hill (left hand panel). 

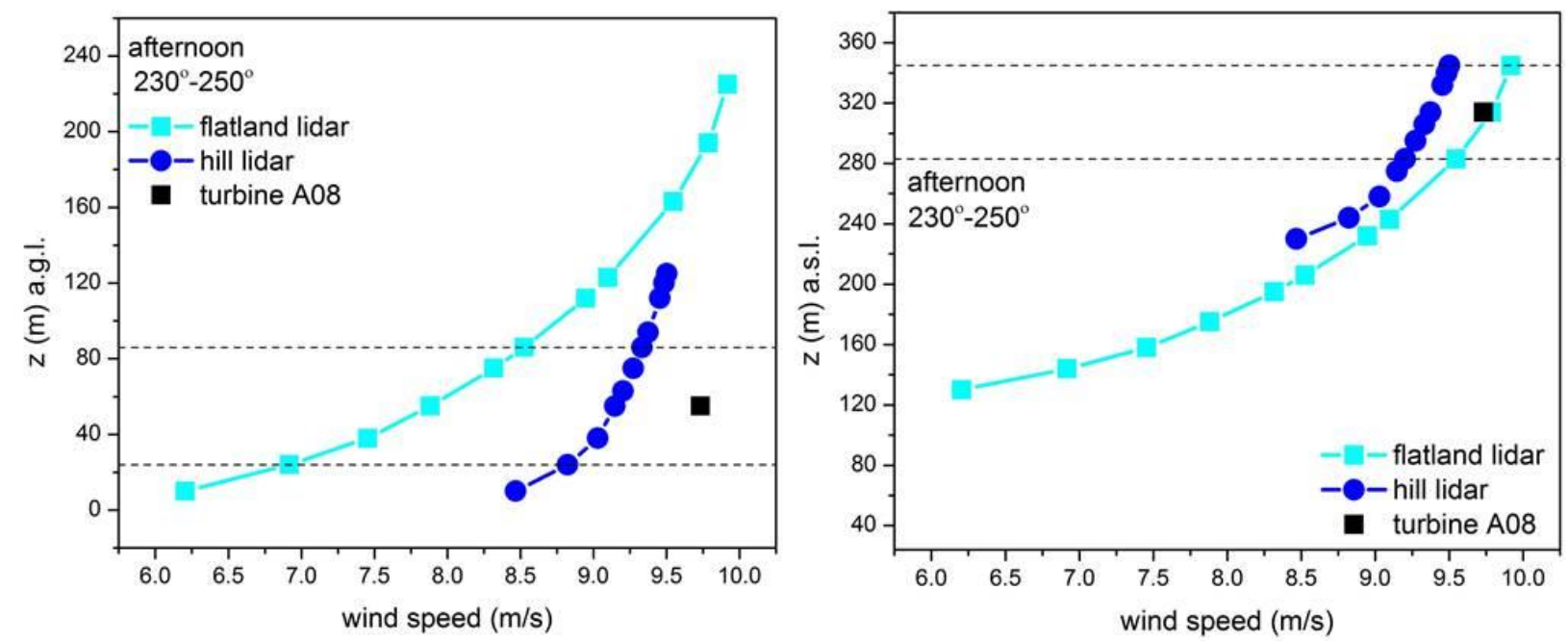

Figure 16: Mean afternoon wind speed profiles and nacelle wind speed as a function of height. A total hill "speed-up" effect is strongly evident and reaches its peak during the afternoon hours (left hand panel). The wind speed at the nacelle (55 $\mathrm{m}$ a.g.l.) is almost equivalent to the wind speed measured at $194 \mathrm{~m}$ a.g.l. at the flatland lidar.
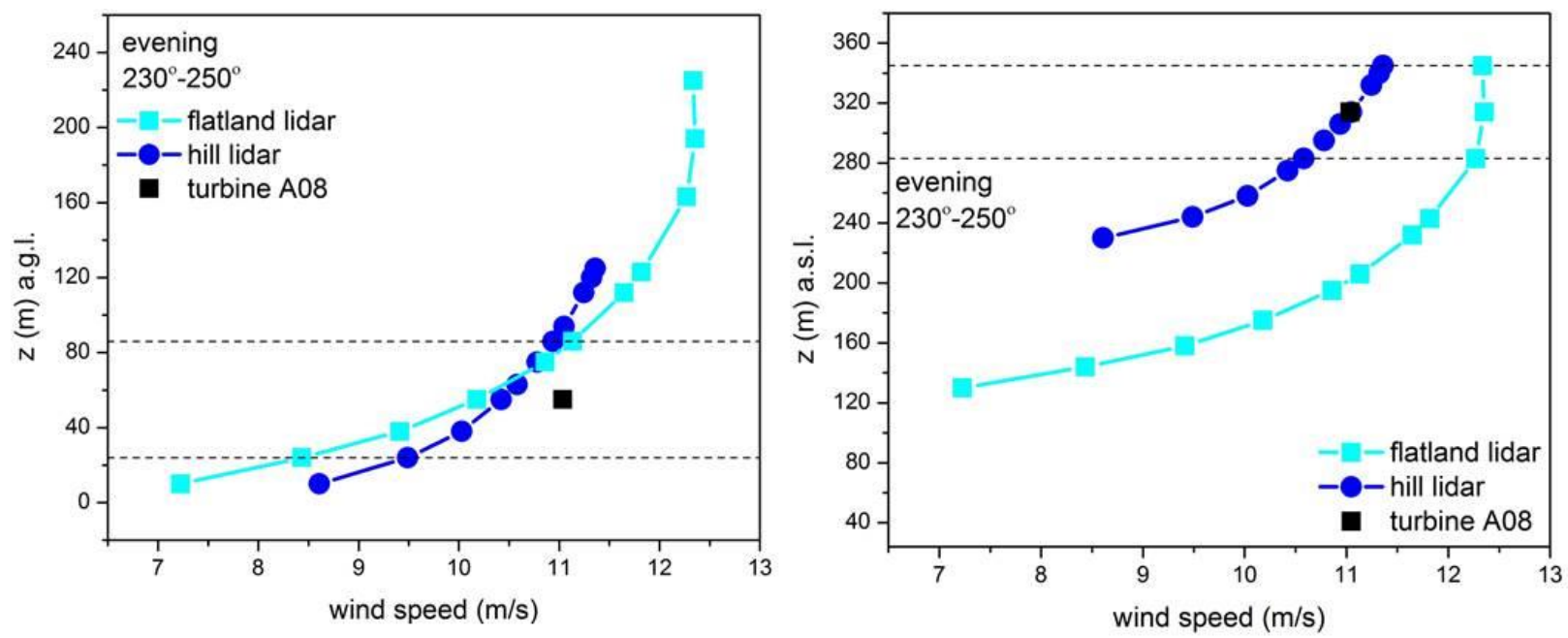

Figure 17: Mean evening wind speed profiles and nacelle wind speed as a function of height. A top-hill "speed up" effect is clearly visible while a total hill "speed up" is there, but is less significant (left hand panel). 

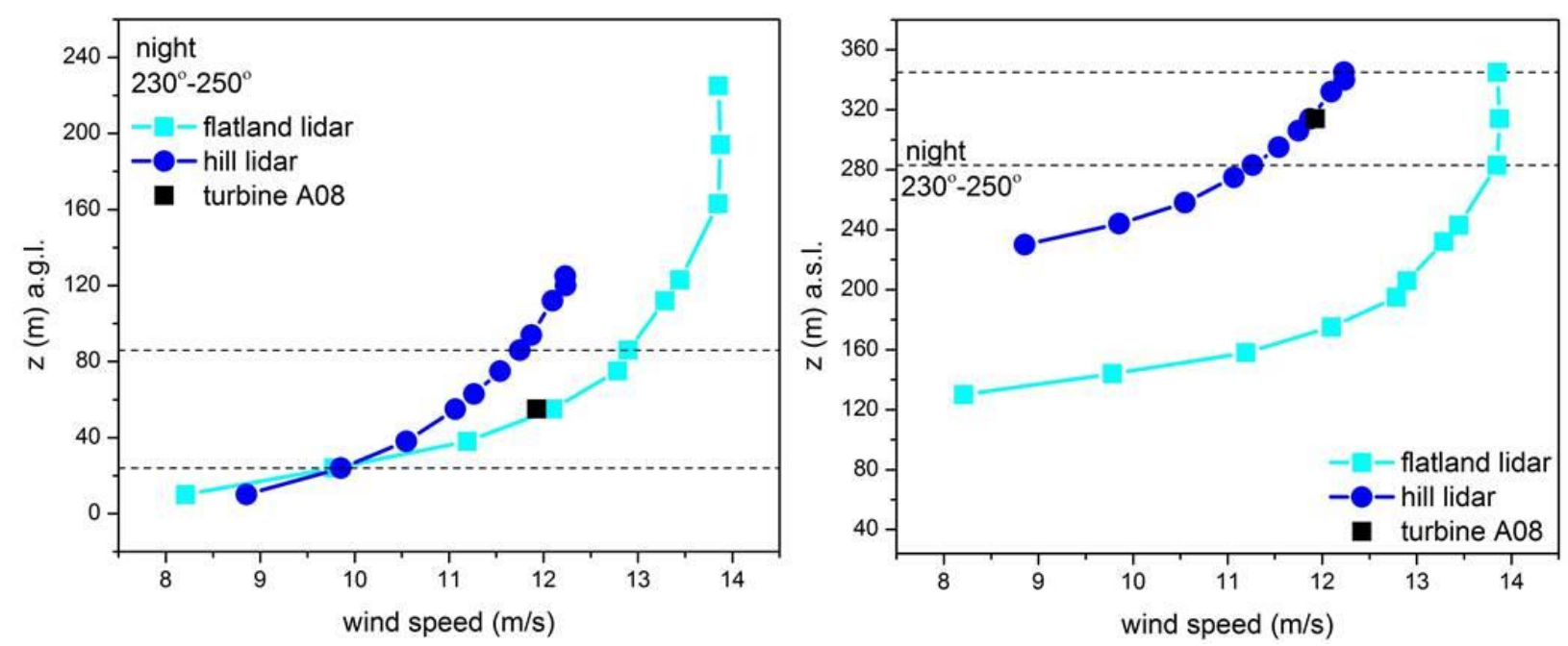

Figure 18: Mean nighttime wind speed profiles and nacelle wind speed as a function of height. A top-hill "speed up" is clearly visible while a total hill "speed up" is not due to high wind speeds at the base of the hill at night (left hand panel).

Although we were not able to calculate an atmospheric stability parameter such as the Richardson number or the Obukhov length due to lack of instrumentation, we can make the assumption that midday hours were convective or well mixed, evening and morning hours were near-neutral, and nighttime hours were stable, as the field campaign occurred during clear-sky conditions on summer days. Using this assumption, we observed an increased top-hill "speed-up" effect with increasing atmospheric stability for the upper portion of the hill. The total hill "speed-up", however, was far less straightforward. The total-hill "speed up" magnitude actually decreased with increasing stability, due to the fact that the wind profiles between the two lidars did not behave as expected. Except during convective conditions, when we did see a "speed up" between the hill lidar and the flatland lidar, this "speed up" was barely observed during neutral conditions and completely absent during stable conditions. In fact, at night, the flatland lidar showed much higher wind speeds at the 55 a.g.l. height than did the hill lidar. The mean flatland lidar 55-m wind speed was almost identical to the wind speed measured by at the uphill turbine in this case. This indicates that wind speeds at $55 \mathrm{~m}$ or above during stable, and to a lesser extend during neutral, periods are much faster at the flatland lidar than initially anticipated. These high wind speeds occur at night and could be caused by strongly channeled flow through the Vasco Road canyon. Additional modeling is needed to verify the significance of this landscape-scale flow feature. 


\section{Lessons learned}

The ZephIR lidars required more power than we had anticipated and we lost a significant portion of nighttime and early morning data due to power losses. The air conditioning units in the lidars drew a lot of power during the hot afternoon hours. This caused the batteries to not fully charge during the day and they drew down faster than expected at night.

Secondly, the flatland lidar was in fact not placed on truly flat land. Although the immediate fetch was flat, there were significant hill features upwind of the flatland lidar which redirected the near-surface flow at night. The flatland lidar also measured very high wind speeds at night, likely due to very strongly channeled flow through the Vasco Road canyon. Reasons for why the flow at the flatland lidar was faster than the hill lidar at night are not yet fully explained as more analysis needs to be done to see why these winds decreased in velocity as they moved along the mid portion of the hill.

Thirdly, the complex terrain introduced errors in the lidar measurements as the flow across the lidar's sample volume was likely not homogenous due to terrain-induced effects. To correct for this, a CFD code is currently being run by Natural Power for the Buena Vista location using high-resolution topographical data. Once this code runs through completion, a "look-up table" of correction values will be provided to us based on measurement height and location. The data will be corrected in this manner for topography effects before any peer-reviewed publication. As such, the data and findings in this report are subject to change.

\section{Warranted future work}

Numerical modeling is needed to better understand the forcing mechanisms behind the regional and local flows. Because of the terrain, modeling local flow will require a Large Eddy Simulation or Immersed Boundary Layer Approach in WRF. Although it will not be easy to model this site at the resolution that is truly needed, it is anticipated that significant insight could be gleaned for hill "speed up" flows from this approach. It is expected that improved wind flow modeling, fully validated with high-resolution lidar data, will lead to improved predictions of power generation for the entire farm.

\section{Upcoming presentations}

This work will be presented at the American Wind Energy Association (AWEA) Wind Resource \& Project Energy Assessment Seminar in Las Vegas, Nevada, in December 2013.

\section{Works cited}

Kaimal, J.C., Finnigan, J.J. (1994) Atmospheric Boundary Layer Flows: Their Structure and Measurement, Oxford University Press, New York, 242p

Taylor, P.A., Teunissen, H.W. (1987) The Askervein Hill project: overview and background data. Boundary-Layer Meteorology 39: 15-39 